\title{
Efeitos ergogênicos da beta-alanina para a performance
}

\section{Ergogenic effects of beta-alanine on performance}

\author{
1 Marcelo Henrique Lage nutrimarcelohenriquelage@gmail.com \\ 2 Elton Bicalho de Souza
}

\footnotetext{
1 Discente do Curso de Nutrição do Centro Universitário de Volta Redonda, UniFOA.

2 Doutor em Ciências, docente do Centro Universitário de Volta Redonda, UniFOA.
}

\section{Resumo}

A beta-alanina é um aminoácido não essencial, produzido endogenamente no fígado. É precursora essencial na produção de carnosina, um dipeptídeo formado por meio de beta-alanina e L-histidina com auxílio da enzima carnosina sintase na intramusculatura esquelética. Atualmente discute-se muito a utilização da beta-alanina como recurso ergogênico. A presente revisão da literatura teve por objetivo descrever os benefícios ergogênicos da suplementação de beta-alanina para exercícios físicos de alta intensidade. Utilizou-se a plataforma Google Acadêmico ${ }^{\circledR}$, com artigos publicados em português e inglês, desde os anos de 2004 até o presente momento. A eficácia da beta-alanina é percebida em exercícios físicos de alta intensidade, atuando no tamponamento intramuscular de íons $\mathrm{H}^{+}$, postergando a fadiga. A parestesia é o efeito colateral mais comumente reportado e a administração da beta-alanina em doses fracionadas ao longo do dia ou por meio de cápsulas de lenta absorção é capaz de minimizar esse efeito. Com relação à dosagem, estudos descrevem que 3 a $6 \mathrm{~g} / \mathrm{dia}$ durante 4 a 10 semanas parecem ser o ideal para o efeito ergogênico dessa substância.

\section{Palavras-chave:}

Beta-alanina. Carnosina. Ácido lático. Suplementos nutricionais.

\begin{abstract}
Beta-Alanine is a nonessential amino acid, endogenously produced in the liver. It is an essential precursor in the production of carnosine, a dipeptide formed by beta-alanine and L-histidine with the aid of carnosine synthase enzyme in skeletal intramusculature. Currently, the use of beta-alanine as an ergogenic resource is much discussed. The present literature review aimed to describe the ergogenic benefits of beta-alanine supplementation for high intensity exercise. The Google Scholar platform ${ }^{\circledR}$ was used, with articles published in Portuguese and English, from 2004 until the present moment. The efficacy of beta-alanine is perceived in high intensity exercise, acting on intramuscular buffering of $\mathrm{H}+$ ions, postponing fatigue. Paresthesia is the most commonly reported side effect, and administration of beta-alanine in fractional doses throughout the day or by slow absorption capsules is able to minimize this effect. Regarding dosage, studies describe that 3 to $6 \mathrm{~g} /$ day for 4 to 10 weeks seems to be ideal for the ergogenic effect of this substance.
\end{abstract}

\section{Keywords:}

Beta-Alanine. Carnosine. Lactic acid. Nutritional Supplements.

\section{Como você deve citar?}

LAGE, Marcelo Henrique; SOUZA, Elton Bicalho de. Efeitos ergogênicos da beta-alanina para a performance. Cadernos UniFOA, Volta Redonda (RJ), v. 16, n. 46, p. 1-5, ago, 2021. 


\section{INTRODUÇÃO}

Exercícios físicos de alta intensidade ou de longa duração podem gerar um acúmulo intramuscular de diversos metabólitos, dentre os quais se destacam a adenosina difosfato (ADP), fósforo inorgânico $(\mathrm{Pi})$, ácido lático, lactato e íons de hidrogênio $\left(\mathrm{H}^{+}\right)$, que podem prejudicar de maneira significativa o desempenho esportivo. Existem contradições sobre o papel que cada metabólito exerce no organismo. Em relação à fadiga, a explicação mais clássica e aceita é relativa ao acúmulo de ácido lático intramuscular. O lactato não exerce nenhum efeito negativo sobre a função contrátil do músculo, entretanto os íons de $\mathrm{H}^{+}$resultantes da dissociação do ácido lático têm real importância na contração muscular, sendo responsáveis por um processo denominado acidose muscular (ARTIOLI; GUALANO; LANCHA JÚNIOR, 2009). $O$ acúmulo de $\mathrm{H}^{+}$proporciona redução do potencial hidrogeniônico $(\mathrm{pH})$, acidificando o meio, contribuindo para a fadiga intramuscular e promovendo uma série de consequências negativas, como redução da tensão músculo-esquelética, inibição da atividade da enzima glicolítica fosfofrutoquinase e limitação da contração muscular (SILVA; SOARES; COELHO, 2015).

Uma maneira eficaz de neutralizar esse efeito é o tamponamento desse elemento. Um recurso ergogênico muito utilizado e com forte evidência científica é a beta-alanina (ARTIOLI; GUALANO; LANCHA JÚNIOR, 2009), um aminoácido que atua no tamponamento intramuscular dos íons $\mathrm{H}^{+}$, revertendo a acidose muscular e promovendo melhora no rendimento (SILVA; SOARES; COELHO, 2015). Diante do exposto, a presente revisão possui o objetivo de descrever os benefícios ergogênicos da suplementação de beta-alanina para exercícios físicos de alta intensidade, bem como seu mecanismo de atuação.

\section{MÉTODOS}

Trata-se de uma revisão narrativa da literatura científica acerca dos efeitos ergogênicos da beta-alanina. Utilizou-se, como plataforma de busca, o Google Acadêmico ${ }^{\circledR}$, com artigos publicados em português e inglês e, para melhor elucidação de mecanismos de ação, livros técnicos de fisiologia, bioquímica e nutrição esportiva foram utilizados para complementação. Como estratégia de busca, foram utilizados os termos de busca "Beta-alanina" or " $\beta$-alanine" and "carnosina" or "carnosine" and "tamponamento" or "tamponade" AND "fadiga muscular" or "muscular fatigue", publicados desde 2004 até 2020.

\section{REVISÃO DA LITERATURA}

A beta-alanina é um aminoácido não essencial produzido no fígado. Identificada pela primeira vez pelo bioquímico russo Vladimir Gulevich, em 1900, é precursor indispensável na produção de carnosina, um dipeptídeo formado pela junção da beta-alanina com L-histidina por meio da enzima carnosina sintase na musculatura esquelética (MATOS et al., 2016). A produção coincide com a via de degradação da uracila no fígado, tendo como produto final o gás carbônico $\left(\mathrm{CO}_{2}\right)$. Apenas uma pequena fração da beta-alanina é perdida nessa via, logo a principal função dessa via é gerar beta-alanina e não degradar $\mathrm{CO}_{2}$ (ARTIOLI et al., 2010).

No entanto, a produção endógena de beta-alanina é extremamente baixa e, como consequência, as concentrações plasmáticas encontram-se muitas vezes próximas de zero. Desse modo, a ingestão desse aminoácido é fundamental para aumentar a sua disponibilidade no organismo (ARTIOLI; GUALANO; LANCHA JUNIOR, 2009).

A carnosina está presente em sua forma íntegra nas carnes. 0 cozimento não reduz o seu conteúdo no alimento, que pode variar de $125-400 \mathrm{mg} / 100 \mathrm{~g}$ de carne, porém ela não pode ser absorvida por 
conta de uma enzima denominada carnosinase, presente no estômago, que rapidamente dissolve esse dipeptídeo em beta-alanina e L-histidina (PAINELLI et al., 2015). Logo, a ingestão de carne com o intuito de aumentar a carnosina é um método ineficaz. Além disso, a histidina tem mais afınidade com a enzima carnosina sintase do que a beta-alanina, e também possui uma concentração significativamente maior do que beta-alanina, fazendo com que a produção de carnosina fique limitada pela disponibilidade de beta-alanina (ZANDONÁ et al., 2018). Possui, como principais funções, ação antioxidante, aumento da sensibilidade miofibrilar ao cálcio, além de participar no tamponamento intramuscular de $\mathrm{H}+$. Quando se fala em efeito ergogênico proporcionado pela beta-alanina no desempenho esportivo, destaca-se o tamponamento (SILVA; SOARES; COELHO, 2015).

Quando ingerida na forma de suplemento, a beta-alanina é absorvida tanto no jejuno quanto no íleo - em taxas semelhantes, e transportada diretamente para a circulação através dos enterócitos. Existem três proteínas que realizam esse transporte: taurine transporter (TauT), Sodium and chloride dependent neutral and basic amino acid transporter - $\mathrm{B}(0+)$ ou SLC6A14, e Proton-assisted amino acid transporter (PAT1 ou SLC36A1). 0 transportador $\mathrm{B}(0+)$ parece ser o mais importante, podendo realizar co-transporte de beta-alanina, cloro $(\mathrm{Cl})$ e sódio $\left(\mathrm{Na}^{+}\right)$. Um substrato comum a esse transportador é a taurina, sugerindo, então, que pode haver competição entre taurina e beta-alanina, se ingeridas concomitantemente. Logo, sugere-se evitar o consumo de taurina para impedir essa competição e, consequentemente, o declínio da absorção de beta-alanina (ARTIOLI et al., 2015).

Ainda segundo Artioli et al. (2015), na musculatura esquelética, os transportadores PAT1 e TauT são capazes de transportar a beta-alanina para o meio intramuscular, favorecendo a síntese de carnosina e promovendo o tamponamento local. 0 tamponamento intramuscular por proteínas, aminoácidos e peptídeos só pode ocorrer por meio de moléculas que contenham imidazol, substância encontrada nos resíduos de histidina, carnosina, anserina e balanina. Ressalta-se que apenas a carnosina pode ser encontrada em humanos, atuando positivamente na regulação do pH intramuscular.

Segundo Maughan et al. (2018), o músculo em repouso possui uma constante de acidez (pKa) de, aproximadamente, 7,0 e, com o trabalho intenso, os ions de $\mathrm{H}^{+}$reduzem a pKa, sendo necessários prótons sequestrantes de $\mathrm{H}^{+}$para a homeostase. A carnosina possui três grupos ionizáveis: o carboxílico (pKa $+2,76)$, amina do resíduo $\beta$-alanina $(\mathrm{pKa}+9,32)$ e átomos de nitrogênio do anel imidazol (pKa $+6,72$ ). Os átomos de nitrogênio do anel imidazol são os responsáveis pela regulação da atividade do sistema tampão intramuscular, pois o valor do pKa é próximo de 7,0, considerado valor ideal do músculo em repouso (FALCÃO, 2016).

A suplementação com beta-alanina é um excelente recurso ergogênico em exercícios físicos de alta intensidade e curta duração (ROSAS et al., 2017), com evidência científica comprovada. De modo geral, a suplementação possui maior potencial ergogênico em indivíduos não treinados e resultados controversos em indivíduos treinados (NADERI et al., 2016; MAUGHAN et al., 2018; BURKE et al., 2019).

Sobre a quantidade de beta-alanina para o potencial efeito ergogênico, doses entre 2 a 6,4g/dia são relatadas (PAINELLI, 2013). Naderi et al. (2016) observaram que a dosagem ideal de beta-alanina para indivíduos que desejam aumentar os níveis de carnosina intramuscular variam de 3 a $6 \mathrm{~g} /$ dia durante um período entre 4 a 10 semanas, porém uma dose de 1,2g/dia para manutenção parece ser mais eficiente. Ainda segundo Naderi et al. (2016), a ingestão de beta-alanina durante refeições que contenham carboidratos parece aumentar as concentrações de carnosina muscular, quando comparada com a ingestão do suplemento de forma livre, provavelmente por conta da ação da insulina. Entretanto, Gonçalves (2019) descarta essa hipótese e descreve que a insulina não é necessária para o transporte de beta-alanina no músculo. Uma vez suplementada, a concentração intramuscular da substância pode se manter por 
até 20 semanas, e o washout (tempo de retorno da carnosina ao seu valor basal) pode variar de 15 a 20 semanas (YAMAGUCHI, 2018).

Segundo Gonçalves (2019), não existe nenhum malefício à saúde com a suplementação de beta-alanina, já que a substância não afeta o conteúdo muscular ou outros órgãos, como fígado e rins. Possíveis efeitos colaterais incluem erupções cutâneas e/ou parestesia, efeito mais reportado, porém esse efeito pode ser facilmente contornado, administrando-se a beta-alanina por meio de cápsulas de lenta absorção ou fracionando-se o consumo ao longo do dia, em intervalos que variam de 3 a 4 horas (NADERI et al., 2016; MAUGHAN et al., 2018).

Os mecanismos moleculares da parestesia ainda não estão muito bem esclarecidos, mas sabe-se que, quando administrada de forma oral, a beta-alanina ativa receptores Mas-related G-protein coupled receptor member $D($ MrgprD), pertecentes às famílias acopladas à proteína $\mathrm{G}$, que desempenha um papel fundamental na mediação de sinais de percepção sensorial. Os receptores MrgprD são localizados nos gânglios da raiz dorsal (GRD), e a beta-alanina parece se ligar diretamente a esses receptores, ativando-os. Como consequência, causam excitabilidade nos neurônios dos GRD, que ecoam diretamente nas percepções sensoriais da pele, acarretando coceira, efeito mais conhecido até o momento da parestesia (GONÇALVES et al., 2020).

\section{CONSIDERAÇÕES FINAIS}

Para efeito ergogênico, a suplementação com Beta-Alanina é altamente recomendável, devido a sua participação essencial na síntese da carnosina, substância que promove o tamponamento intramuscular neutralizando os íons $\mathrm{H}^{+}$, responsáveis por dor e fadiga.

A maioria dos estudos indica uma posologia que varia entre $3 \mathrm{a} 6 \mathrm{~g} / \mathrm{dia}$, por um período de 4 a 10 semanas. Ressalta-se que, para melhor resultado decorrente da suplementação de beta-alanina, deve-se evitar a administração concomitante de taurina. A parestesia é o efeito colateral mais relatado e, para se evitar essa adversidade, deve-se administrar a beta-alanina em doses fracionadas ao longo do dia ou por meio de cápsulas de lenta absorção.

Por fim, ressalta-se que se trata de um suplemento indicado para atividades de alta intensidade, não existindo a necessidade da ingestão desse ergogênico com nenhuma outra substância para a potencialização dos efeitos.

\section{REFERÊNCIAS}

ARTIOLI, G.G.; GUALANO, B.; SMITH, A.; STOUT, J.; LANCHA JUNIOR, A.H. Role of beta-alanine supplementation on muscle carnosine and exercise performance. Medicine and Science in Sports and Exercise, v. 42, n. 6, p.1162-1173, 2010.

ARTIOLI, G.G.; GUALANO, B.; LANCHA JUNIOR, A.H. Suplementação de $\beta$-alanina: uma nova estratégia nutricional para melhorar o desempenho esportivo. Revista Mackenzie de Educação Física e Esporte, v. 8, n. 1, p. 41-56, 2009.

FALCÃO, L.E.M. $\beta$-alanina e sua ação ergogênica nutricional no exercício: evidências atuais. Revista Brasileira de Nutrição Esportiva, v. 10, n. 57, p.361-368, 2016. 
GONÇALVES, L.S. Ação da insulina na captação de beta-alanina pelo músculo esquelético: efeito sobre o conteúdo de beta-alanina muscular e mecanismos envolvidos. Tese de Doutorado. Escola de Educação Física e Esporte (EEFE). São Paulo: Universidade de São Paulo - USP, 2019.

GONÇALVES, L.S. et al. Insulin does not stimulate $\beta$-alanine transport into human skeletal muscle. Am J Physiol Cell Physiol. v. 318, n. 4, p. 777-786, 2020.

MAUGHAN, R.J. et al. IOC consensus statement: dietary supplements and the high-performance athlete. British Journal of Sports Medicine, v. 1, n. 17, p. 1-17, 2018.

NADERI, A.; OLIVEIRA, E.P.; ZIEGENFUSS, T.N.; WILLEMS, M.E.T. Timing, optimal dose and intake duration of dietary supplements with evidence-based use in sports nutrition. Journal of exercise nutrition \& biochemistry, v. 20, n. 4, p. 1-12, 2016.

PAINELLI, V.S.; FREITAS, P.; GUALANO, B.; ARTIOLI, G.G. Metabolismo de carmosina, suplementação de $\beta$-alanina e desempenho físico: atualização - parte I. Revista brasileira de nutrição esportiva, v. 9, n. 52, p.361-378, 2015.

PAINELLI, V.S. Influência do estado de treinamento sobre o desempenho físico em resposta à suplementação de beta-alanina. Tese de Mestrado. Escola de Educação Física e Esporte (EEFE). São Paulo: Universidade de São Paulo - USP, 2013.

SILVA, C.M.; SOARES, E.A.; COELHO, G.M.O. Suplementação de $\beta$-alanina em atletas praticantes de atividade física e sedentários. Revista Brasileira de Prescrição e Fisiologia do Exercício, v. 9, n. 56, p. 575-591, 2015.

YAMAGUCHI, G.C. Efeito da cinética de washout de carnosina muscular após a suplementação de beta-alanina. Tese de Mestrado. Escola de Educação Física e Esporte (EEFE). São Paulo: Universidade de São Paulo - USP, 2018.

ZANDONÁ, B.A.; OLIVEIRA, C.D.S.; ALVES, R.C.; SMOLAREK, A.C.; SOUZA JUNIOR, T.P. Efeito da suplementação de beta-alanina no desempenho: Uma revisão crítica. Revista Brasileira de Nutrição Esportiva, v. 12, n. 69, p.116-124, 2018. 